\title{
Rancang Bangun Papan Informasi Digital (Digital Signage) Berbasis Web Menggunakan Sistem Operasi Linux dengan Server NGINX pada STMIK Rosma Karawang
}

\author{
Lila Setiyani $^{*}$, Jaka Abdul Haris ${ }^{2}$, Evelyn Tjandra ${ }^{3}$ \\ ${ }^{123}$ STMIK Rosma Karawang \\ *lila.setiyani@dosen.rosma.ac.id
}

\begin{abstract}
Information technology is the result of human thought to develop certain procedures or systems and use them to solve problems in his life. Submission of information at this time is no longer through print media, but will gradually shift to the use of electronic digital media. An announcement can be interpreted as a message delivered to everyone who becomes the goal or target of the intended information. This study discusses Digital Signage (announcement information system) which can replace the conventional announcement media / wall magazine board (mading). The form of Digital Signage is used in computers by connecting to a monitor to display digitalbased information in one direction. This announcement information makes each division in STMIK ROSMA no longer need to print and paste announcements on the information boards available, but can digitally enter the announcement into the system and then the announcement will be displayed on the monitor screen available in the campus lobby area. This can make the process of delivering information more effective and efficient when compared with print media.
\end{abstract}

Keywords: digital information, digital signage, information systems, media information, college

\begin{abstract}
Abstrak
Teknologi informasi merupakan hasil pemikiran manusia untuk mengembangkan prosedur atau sistem tertentu dan menggunakannya untuk memecahkan masalah dalam hidupnya. Penyampaian informasi saat ini tidak lagi melalui media cetak, tetapi secara bertahap akan bergeser ke penggunaan media digital elektronik. Pengumuman dapat diartikan sebagai pesan yang disampaikan kepada setiap orang yang menjadi tujuan atau sasaran dari informasi yang dimaksud. Penelitian ini membahas tentang Digital Signage (sistem informasi pengumuman) yang dapat menggantikan media pengumuman konvensional / papan majalah dinding (mading). Bentuk Digital Signage digunakan di komputer dengan menghubungkan ke monitor untuk menampilkan informasi berbasis digital dalam satu arah. Informasi pengumuman ini membuat setiap divisi di STMIK ROSMA tidak perlu lagi mencetak dan menempelkan pengumuman di papan informasi yang tersedia, melainkan dapat memasukkan pengumuman tersebut secara digital ke dalam sistem dan kemudian pengumuman tersebut akan ditampilkan di layar monitor yang tersedia di area lobby kampus. Hal ini dapat menjadikan proses penyampaian informasi lebih efektif dan efisien jika dibandingkan dengan media cetak.
\end{abstract}

Kata kunci: informasi digital, digital signage, sistem informasi, media informasi, perguruan tinggi

\section{Pendahuluan}

Pada era revolusi industri 4.0 saat ini, teknologi menjadi bagian terpenting dalam kehidupan kita. Hal tersebut, mengakibatkan teknologi berkembang pesat, diantaranya adalah internet dan digitalisasi. Kedua teknologi tersebut, saling mendukung dan menghilangkan batas ruang dan waktu yang berdampak pada semua bidang.

Bidang pendidikan mulai mengadopsi teknologi internet dan digitalisasi dalam proses bisnisnya. Ini dilakukan sebagai salah satu strategi untuk meningkatkan efektifitas dan efisiensi dalam pengelolaan manajemennya. Bidang pendidikan yang telah banyak mengimplementasikan 
teknologi salah satunya adalah perguruan tinggi. Institusi ini memproses sumber daya manusia menjadi sumber daya yang bernilai dan bermanfaat. Idealnya perguruan tinggi mengimplementasikan teknologi untuk meningkatkan efektivitas dan efisiensi dari proses bisnisnya. Salah satu hal yang terpenting adalah penerapan sistem informasi yang didukung teknologi. Sistem informasi berfungsi memproses input berupa data untuk dijadikan informasi yang memiliki nilai. Informasi pada perguruan tinggi menjadi sangat penting karena dapat memberikan arahan kepada seluruh civitas perguruan tinggi dalam melaksanakan aktivitasnya.

Idealnya civitas perguruan tinggi khususnya mahasiswa menerima informasi dari manajemen melalui media-media informasi yang reliable dan valid, agar pelayanan manajemen terhadap mahasiswa lebih. Media-media informasi itu dapat berupa layanan helpdesk berbasis website, customer service, call center, papan informasi, dan lain-lain.

STMIK Rosma merupakan institusi perguruan tinggi yang berfokus pada pendidikan komputer, dalam proses bisnis pemberian informasi kepada mahasiswa menggunakan media papan informasi diantaranya papan informasi akademik, keuangan, organisasi, dan umum. Namun, papan informasi yang ada masih memiliki beberapa keterbatasan diantaranya informasi yang tidak tersampaikan kepada mahasiswa hanya karena mahasiswa tidak bisa untuk datang ke kampus, selain itu juga penggunaan papan informasi yang banyak letaknya menyulitkan saat pencarian informasi terbaru, karena mahasiswa harus mengecek tiap-tiap papan informasi untuk mendapatkan informasi terbaru.

Oleh sebab itu, peneliti tertarik untuk membangun papan informasi digital yang dapat meningkatkan efektifitas dan efisiensi proses bisnis penyampain informasi dari manajemen STMIK Rosma kepada mahasiswa menggunakan pendekatan digital signage. Untuk itu, peneliti mengambil judul

$\begin{array}{lrr}\text { "RANCANG } & \text { BANGUN } & \text { PAPAN } \\ \text { INFORMASI } & \text { DIGITAL } & \text { (DIGITAL } \\ \text { SIGNAGE) } & \text { BERBASIS } & \text { WEB } \\ \text { MENGGUNAKAN } & \text { SISTEM } & \text { OPERASI }\end{array}$

LINUX DENGAN SERVER NGINX PADA STMIK ROSMA KARAWANG”.

\subsection{Sistem Informasi}

Sistem informasi merupakan suatu sistem yang menyediakan untuk membantu perusahaan dalam memanajemen dalam pengambilan keputusan dan menjalankan operasional perusahaan, dimana dalam sistem tersebut terdapat human, teknologi informasi dan prosedur - prosedur [1]

Menurut Mc leod (1998) dalam [2] Sistem Informasi adalah suatu system dalam suatu organisasi yang mempertemukan kebutuhan pengolahan transaksi harian, mendukung orerasi, bersifat manajerial, dan kegiatan strategi dari suatu organisasi dan menyediakan pihak luar tertentu dengan laporan laporan yang dibutuhkan. Sedangkan menurut Jogiyanto (1989) dalam [3] Sistem informasi adalah suatu sistem organisasi yang mempertemukan kebutuhan pengolahan transaksi harian, mendukung operasi, bersifat manajerial dan kegiatan strategi dari suatu organisasi dan menyediakan pihak luar tertentu dengan laporan-laporan yang diperlukan.

\subsection{Webserver}

Web Server merupakan sebuah perangkat lunak dalam server yang berfungsi menerima permintaan (request) berupa halaman web melalui HTTP atau HTTPS dari klien yang dikenal dengan browser web dan mengirimkan kembali (response) hasilnya dalam bentuk halaman-halaman web yang umumnya berbentuk dokumen HTML [4].

Web server adalah sebuah bentuk server yang khusus digunakan untuk menyimpan halaman website atau homepage. Dalam melakukan permintaan suatu halaman pada suatu situs web, browser melakukan koneksi ke suatu server dengan protocol HTTP. Server akan menanggapi koneksi tersebut dengan mengirimkan isi file yang diminta dan memutuskan koneksi tersebut. Browser kemudian mengolah informasi yang didapat dari server. Pada bagian server, browser yang berbeda dapat melakukan koneksi pada server yang sama untuk memperoleh informasi yang sama. Data ini mempunyai format yang standar, disebut dengan format SGML (Standart General Markup Language). Data yang berupa format ini kemudian akan 
ditampilkan oleh browser sesuai dengan kemampuan browser tersebut. Web server yang terkenal diantaranya adalah Apache. Web server merupakan software yang menjadi tulang punggung dari World Wide Web (WWW). [5]

\subsection{Unified Modeling Language (UML)}

Unified Modeling Language (UML) menggambarkan desain sistem dan fungsi masing-masing user, dalam arti luas UML merupakan salah satu alat bantu yang sangat handal di dunia pengembangan sistem yang berorientasi obyek. Hal ini disebabkan karena UML menyediakan bahasa permodelan visual yang memungkinkan bagi pengembang sistem untuk membuat cetak biru atas visi mereka dalam bentuk yang baku, mudah dimengerti serta dilengkapi dengan mekanisme yang efektif untuk berbagi (sharing) dan mengkomunikasikan rancangan mereka dengan yang lain [6]. Sedangkan menurut [7] Unified Modeling Language (UML) adalah bahasa untuk visualisasi, membangun sistem perangkat lunak, serta dokumentasi. UML menyediakan modelmodel yang tepat, tidak ambigu, dan lengkap. Secara khusus UML menspesifikasi langkahlangkah penting dalam pengembangan keputusan analisis, perancangan, serta implementasi dalam sistem perangkat lunak. UML bukanlah merupakan bahasa pemrograman tetapi model-model yang tercipta berhubungan langsung dengan berbagai macam bahasa pemrograman.

\subsection{Server NGINX}

Dalam penelitian ini penulis menggunakan server NGINX karena dalam pengalaman penulis yang sudah menggunakannya selama 1 tahun, tidak pernah terjadi trouble dan kecepatan memuat yang sangat baik, dikemukakan oleh laman NGINX sendiri bahwa:

"NGINX is open source software for web serving, reverse proxying, caching, load balancing, media streaming, and more. It started out as a web server designed for maximum performance and stability. In addition to its HTTP server capabilities, NGINX can also function as a proxy server for email (IMAP, POP3, and SMTP) and a reverse proxy and load balancer for HTTP, $T C P$, and UDP servers." [8]
NGINX adalah salah satu web server yang penggunanya saat ini (Awal 2019) sudah mencapai 300 juta. Selain web server NGINX menawarkan fitur lainnya seperti: load balancer, applicatioin delivery content, microservice, content caching, security control, dan proxy [9]. Dapat disimpulkan bahwa Server NGINX merupakan web server, yang memiliki beberapa fitur tambahan yang dibutuhkan untuk development dan production sistem seperti load balancer, dan content caching.

\subsection{Framework Codeigniter}

Salah satu framework yang paling banyak digunakan didunia adalah framework codeigniter dengan pertimbangan yang mudah digunakan karena selain menggunakan metode MVC yaitu Model View dan Controller juga karena Codeigniter sudah memiliki library yang lengkap termasuk disisi kemanannya. Codeigniter merupakan salah satu framework PHP. Secara garis besar, Codeigniter sudah menerapkan proses pembuatan kode yang rapi dan terorganisir, sehingga memudahkan dalam proses pengembangan sistem. [10]. Sedangkan menurut [11] dalam jurnalnya Development of Information System Based on Web Application for Measuring Educational Performance Indicator Using Codeigniter Framework, mengemukakan "Codeigniter is an open source web application framework that is used to build dynamic php applications.5 The main purpose of Codeigniter development is to help developers to work on applications faster than writing all the code from scratch. Codeigniter provides a variety of libraries that can simplify the development. Codeigniter was introduced to the public on February 28, 2006."

Dapat disimpulkan bahwa codeigniter merupakan framework dari bahasa pemrograman PHP yang dibuat untuk membantu para pengembang dalam proses membangun program, ini dikarenakan codeigniter menyediakan library untuk menyederhanakan sebuah kode.

\subsection{Digital Signage}

Point utama pembahasan teori-teori ini adalah mengenai Digital Signage, Digital Signage sendiri sudah digunakan dibanyak 
bidang seperti billboard, banner dihotel, papan skor, dan lainnya, seperti yang dikemukakan oleh [12] bahwa:

Digital signage is a very compelling technology. The medium has "stickiness"; few people will not at the very least, glance at or pay attention to a plasma or LCD display. It's a communication system that's effective, immediate, and dynamic. It can be used in a variety of building types Video displays come in a wide variety of sizes and core technologies. Selection of a display is based on the dimensions of the viewing area, lighting, and the type of content and materials to be displayed. The most popular displays are plasma screens and liquid crystal displays.

\section{Metoda Penelitian}

\subsection{Pengembangan Sistem}

Pada tahap ini pengembangan sistem yang digunakan penulis adalah Agile Unified Process (AUP). Agile Unified Process (AUP) merupakan pendekatan yang menyediakan suatu susunan yang bersifat serial yaitu urutan linier dari kegiatan rekayasa perangkat lunak yang memungkinkan sebuah tim perangkat lunak memvisualkan keseluruhan aliran proses untuk sebuah model perangkat lunak, namun dalam setiap kegiatan, tim berulang untuk mencapai kecepatan dan untuk memberikan peningkatan perangkat lunak yang berarti kepada pengguna akhir secepat mungkin [1]. Fase AUP model dapat digambarkan sebagai berikut:

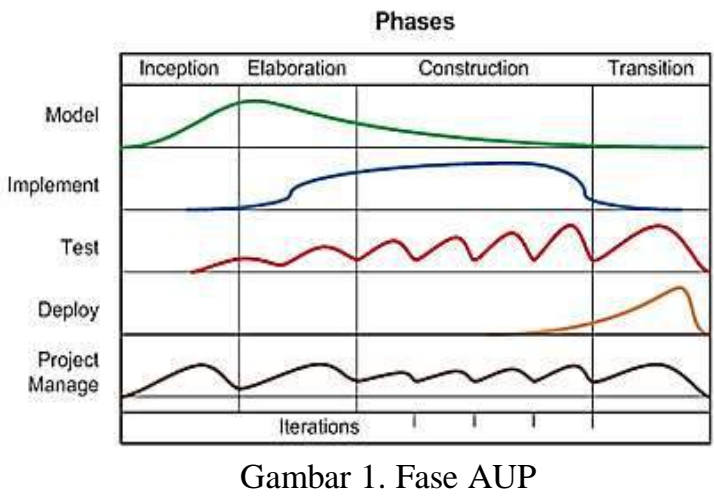

\section{a. Inception}

Inception Identifikasi secara objektif jangkauan awal dari sistem yang akan dikembangkan. Aktifitas yang dilakukan pada tahap ini diantaranya analisis sistem, perumusan target dari sistem yang dikembangkan, identifikasi kebutuhan sistem, perancangan pengujian sistem, membuat model alur rencana sistem dengan menggunakan diagram dan dilakukannya pembuatan dokumentasi.

\section{b. Elaboration}

Elaboration Menetapkan dan melakukan rancangan dari sistem sesuai dengan hasil yang didapat dalam tahap inception. aktifitas utama yang dilakukan pada tahap ini mencakup pembuatan desain arsitektur sistem, desain komponen sistem, desain format data dalam database, desain interface / tampilan sistem, membuat model pada diagram UML dan pembuatan dokumentasi..

\section{c. Construction}

Construction Tahap untuk melakukan implementasi sesuai dengan hasil yang didapat dari tahap inception dan elaboration yang sesuai dengan kebutuhan user. Pada tahap ini dilakukan terlebih dahulu pemeriksaan ulang semua desain sistem meliputi komponen kebutuhan sistem dan diagram rancangan sistem. Setelah dirasa hasil analisa rancangan sistem cukup dan sesuai maka dapat dilakukan implementasi sistem dengan bahasa pemrograman tertentu. Aktivitas lain yang dilakukan pada tahap ini mencakup pengujian hasil analisa dan desain, pendataan kebutuhan implementasi, pembuatan program, pengujian secara sederhana, pendataan berbagai kemungkinan pengembangan/perbaikan lebih lanjut dan pembuatan dokumentasi.

\section{d. Transition}

Transition melakukan validasi dan integrasi sistem dengan yang berhubungan dengan sistem. Tahapan yang dilakukan adalah menyerahkan sistem aplikasi ke user disertai pula pelaksanaan pelatihan sistem kepada user dan testing aplikasi terhadap keinginan user. Dilakukan pula dokumentasi untuk tahap transition diantaranya pengujian dan pendataan jika terjadi eror. AUP menggunakan alur kerja yang linear, namun di tiap aktivitas dilakukan iterasi sehingga secepat mungkin dapat menghasilkan produk perangkat lunak yang lebih baik.

Dengan iterasi yang diadopsi untuk disesuaikan dengan tahapan penelitian yang ada sebagai berikut: 


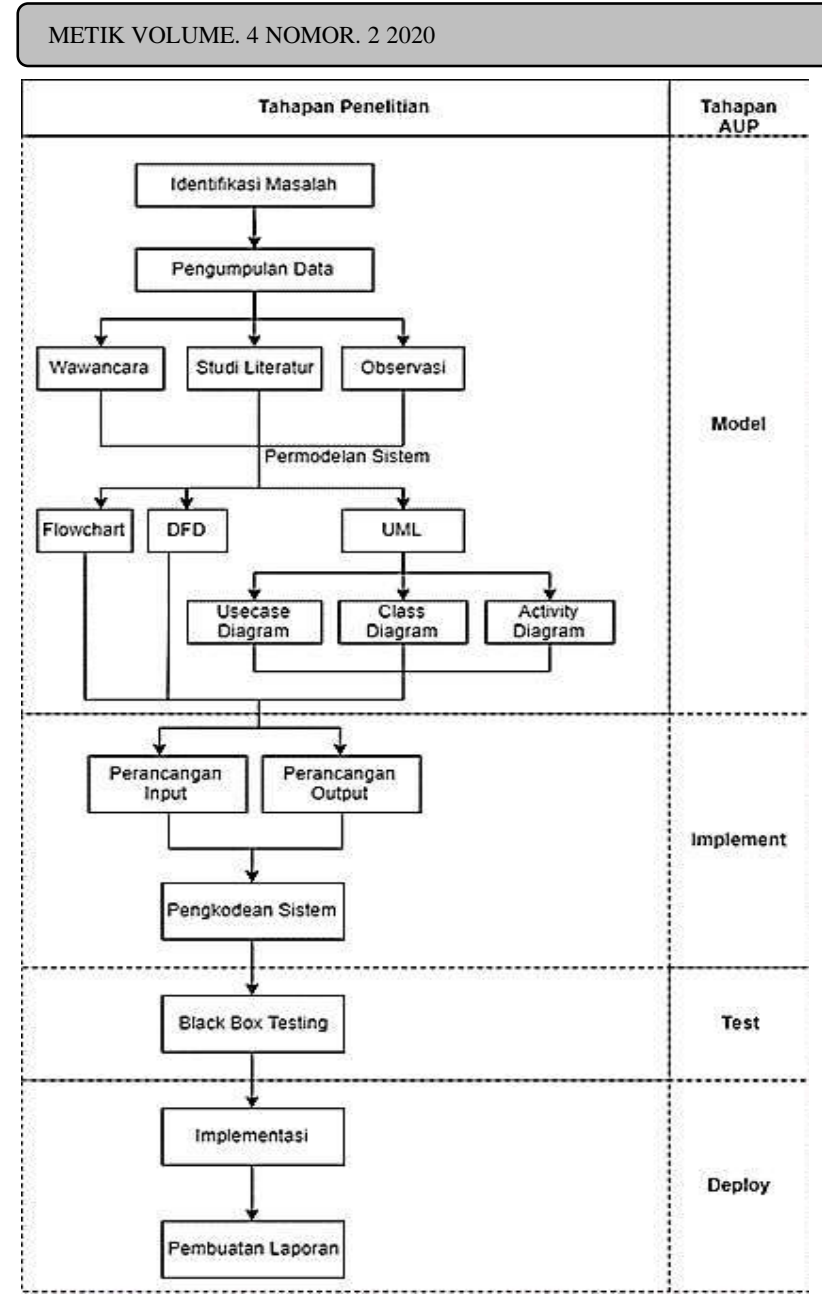

Gambar 2. Adopsi Metodologi Penelitian

\section{a. Modelling}

Modelling memahami proses bisnis dari studi kasus, bidang masalah yang ada dalam studi kasus, dan menemukan solusi yang tepat dalam menangani permasalahan dalam studi kasus. Solusi yang digunakan berupa perancangan diagram sistem seperti bisnis usecase, usecase diagram, class diagram, desain interface dan desain database. Iterasi modelling lebih banyak dilakukan dalam tahapan inception dan elaboration.

b. Implementasi

Proses menerjemahkan konsep kedalam bentuk source code. Diuji secara dasar dan diuji dalam letak tertentu. Implementation digunakan pada tahapan elaboration dalam melakukan implementasi perancangan diagram kebutuhan sistem dan pada tahap construction sebagai implementasi desain sistem kedalam bahasa pemrograman. Diuji dalam letak tertentu. Implementation digunakan pada tahapan elaboration dalam melakukan implementasi perancangan diagram kebutuhan sistem dan pada tahap construction sebagai implementasi desain sistem kedalam bahasa pemrograman.

c. Test

Mendesain dan melakukan pengujian untuk memastikan apakah hasil rancangan maupun implementasi yang telah dibuat sesuai dengan kebutuhan. Testing dilakukan mulai dari tahap elaboration sebagai pengujian hasil rancangan sistem dan pada tahap construction sebagai pengujian modulmodul yang ada dalam sistem sedangkan dalam tahap transition sebagai pengujian terhadap kepuasan user.

d. Deploy

Tahapan penerimaan software oleh user dan evaluasi dari user. Iterasi ini hanya dilakukan dalam tahapan construction akhir menuju tahap transition sebagai salah satu aktifitas integrasi sistem dari pengembang kepada user. Dapat disimpulkan bahwa AUP merupakan metodologi pendekatan pengembangan sistem modern yang memungkinkan seluruh tim untuk memvisualisasikan alur proses permodelan perangkat lunak, sehingga proses pengembangan sistem menjadi cepat dan menghasilkan produk perangkat lunak yang lebih baik.

\section{e. Front End dan Back End}

Front-End dari sebuah website adalah bagian yang langsung dilihat oleh user. User juga bisa langsung berinteraksi pada bagian ini, sedangkan Back-End adalah bagian belakang layar dari sebuah website. Bahasa pemrograman yang digunakan untuk backend yaitu PHP dengan Framework Codeigniter, untuk penulisan kode pemograman menggunakan Visual Studio Code, Database MySQL dan server NGINX.

\subsection{Metode Pengumpulan Data}

Metode pengumpulan data yang digunakan penulis pada penelitian ini, yaitu:

a. Observarsi untuk mengumpulkan data yang dilakukan dengan cara melakukan pengamatan dan pencatatan secara langsung ke lapangan di STMIK Rosma Karawang.

b. Studi literatur melalui jurnal dan buku yang terkait dengan masalah yang dibahas, seperti gambaran singkat STMIK Rosma, pengertian perancangan sistem, dan pengertian Digital Signage.

c. Wawancara, agar mendapatkan informasi 
yang berkaitan serta akurat dengan penulisan skripsi ini, penulis mewawancarai Mahasiswa, Dosen, dan Staff Biro Administrasi Akademik dan Kemahasiswaan (BAAK)

STMIK Rosma Karawang.

\section{Hasil Penelitian}

\subsection{Unified Modeling Language (UML)}

Use Case Diagram pada penelitian ini menggambarkan hubungan antar aktor dengan sistem dalam hal fungsional. Use case diagram adalah gambaran interaksi antara pengguna sistem atau user (actor) dengan kasus (use case) yang telah disesuaikan dengan sistem yang sedang dikembangkan. Use case mendeskripsikan sebuah interkasi antara satu atau lebih aktor dengan sistem informasi yang akan dibuat. Use case diagram merupakan deskripsi lengkap tentang interaksi yang terjadi antara para aktor dengan sistem. Use case diagram yang dibuat untuk menggambarkan sistem yang baru. Use case diagram keseluruhan sistem memiliki 2 aktor yaitu mahasiswa, bagian umum, dosen, ketua STMIK Rosma, dan author/admin. Setiap aktor memiliki use case yang berbeda. Dan setiap use case mewakili langkah-langkah dari setiap aktor sehingga gambaran sistem lebih jelas dan memudahkan dalam merancang sistem informasi.

Berikut ini kebutuhan pengguna untuk Bagian Umum.

a. Mengolah data dan hak akses user.

b. Mengolah data master.

c. Mengolah data mata kuliah.

d. Mengolah data dosen.

e. Mengolah data pengampu.

f. Mengolah data ruang.

g. Mengolah data pengumuman.

h. Mengolah data berita.

i. Mengolah data event.

j. Mengolah menu.

Kebutuhan Mahasiswa:

a. Melihat pengumuman.

b. Melihat berita.

c. Melihat event.

d. Melihat jadwal kuliah.

e. Melihat ringkasan materi.

Kebutuhan Dosen:

a. Membuat materi.

b. Melihat pengumuman. c. Melihat berita.

d. Melihat event.

e. Melihat jadwal kuliah.

f. Melihat ringkasan materi.

Kebutuhan Ketua STMIK Rosma:

a. Verifikasi pengumuman.

b. Verifikasi berita.

Kebutuhan Author/Admin:

a. Membuat berita.

b. Membuat pengumuman.

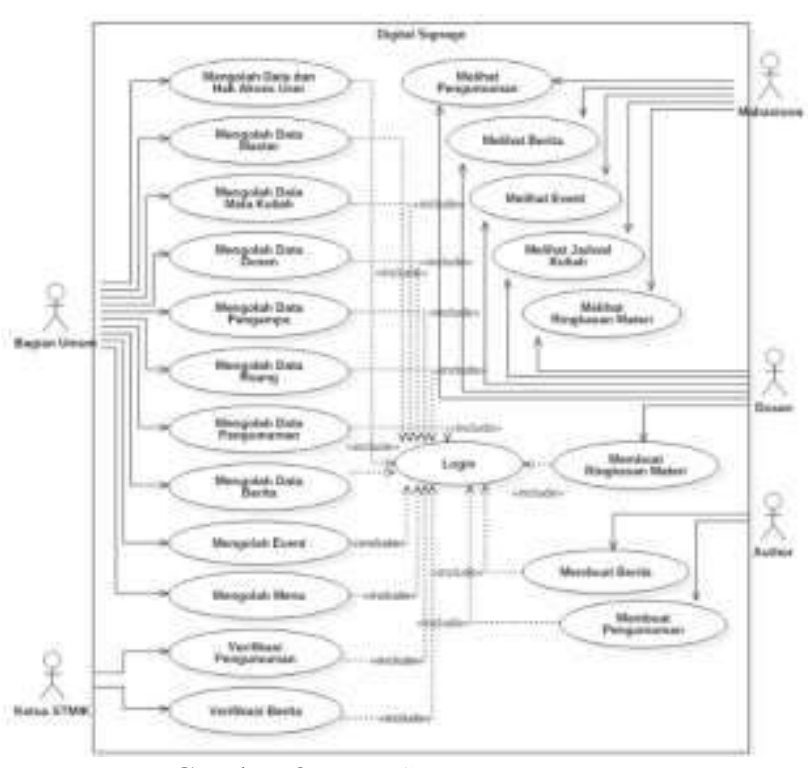

Gambar 3. Use Case Diagram

\subsection{Class Diagram}

Diagram kelas atau Class diagram menggambarkan stuktur sistem dari segi pendefinisian kelaskelas yang akan dibuat untuk membangun sistem. Kelas (class) didefinisikan sebagai kumpulan/himpunan objek yang memiliki kesamaan dalam atribut/property, perilaku (operasi), serta cara berhubungan dengan objek lain. Class diagram dalam penelitian ini adalah sebagai berikut. 




Gambar 4. Class Diagram

\subsection{Implementasi}

\section{a. Tampilan Login}

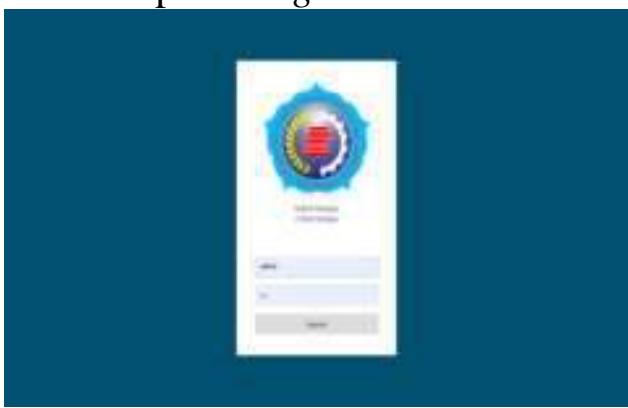

Gambar 5. Tampilan Login

b. Tampilan Utama Digital Signage

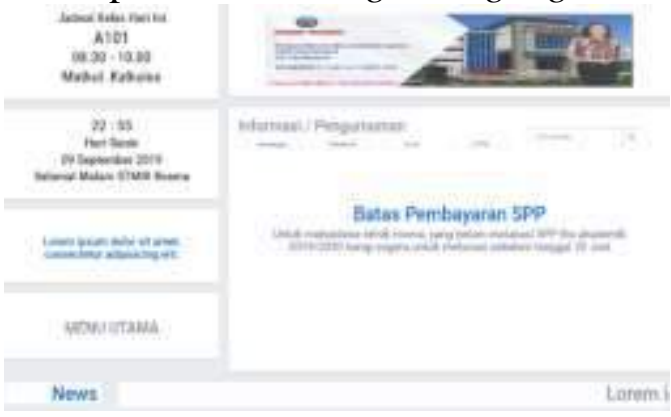

Gambar 6. Tampilan Utama Digital Signage

c. Tampilan Menu

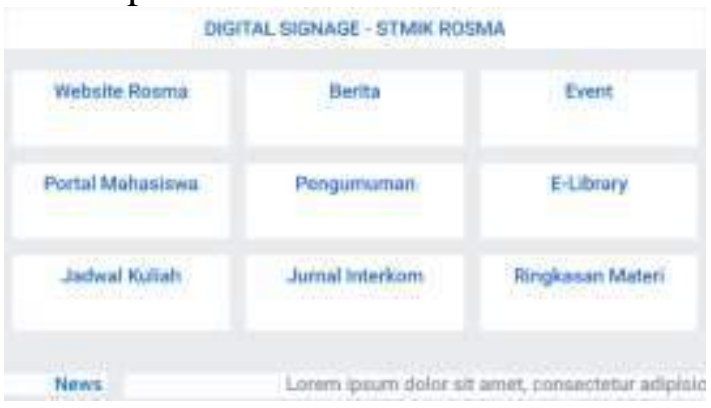

Gambar 7. Tampilan Menu

d. Tampilan Halaman Event

DIGITAL SIGNAGE-STMIK ROSMA

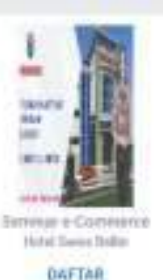

GafThe

News

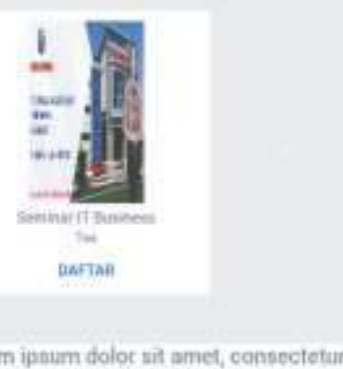

Lorem ipnum dolor sit amet, consectetur

Gambar 8. Tampilan Halaman Event

e. Tampilan Halamam Pengumuman DIGITAL SIGNAGE - STMIK ROSMA

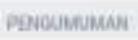

Pmati

Fited Pangaian FFES

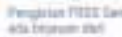

Don

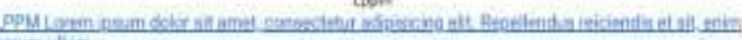
mivimilam.

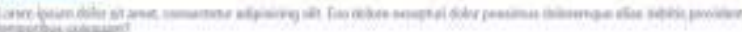

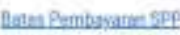

Keumea

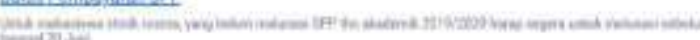

Lorem ipsiam dolor at amet, consectefur adi

Gambar 9. Tampilan Halaman Pengumuman

\section{f. Tampilan Halaman Berita}

DIGITAL SIGNAGE - STMIK ROSMA

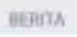

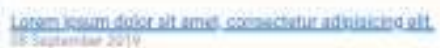

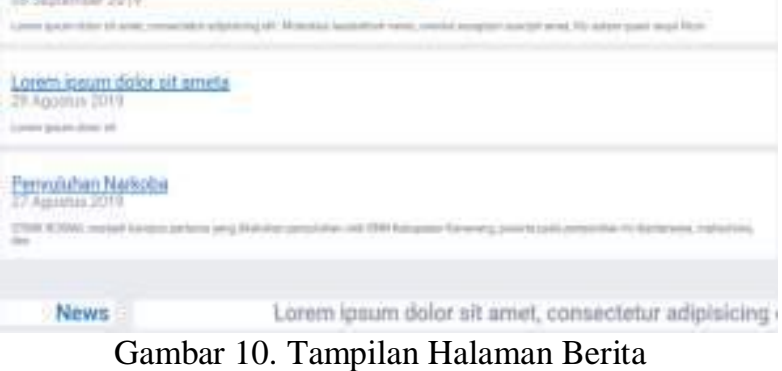

g. Tampilan Manajemen Event



Dime Even Timp:

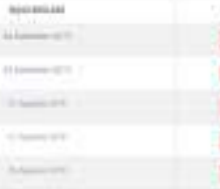

Ptaing:

Gambar 11. Tampilan Manajemen Event 


\section{h. Tampilan Manajemen Berita}
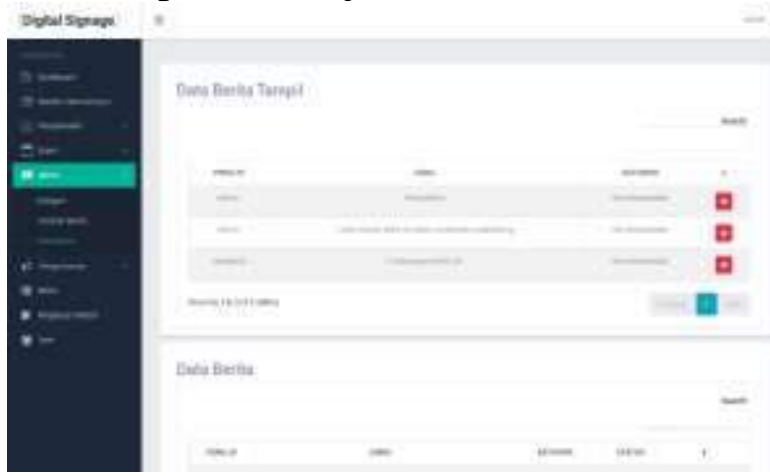

Gambar 12. Tampilan Manajemen Berita

i. Tampilan Manajemen Menu
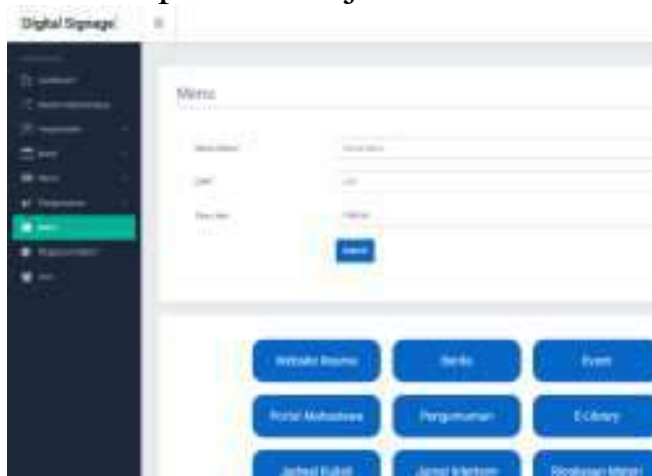

Gambar 13. Tampilan Manajemen Menu

j. Tampilan Manajemen Penumuman
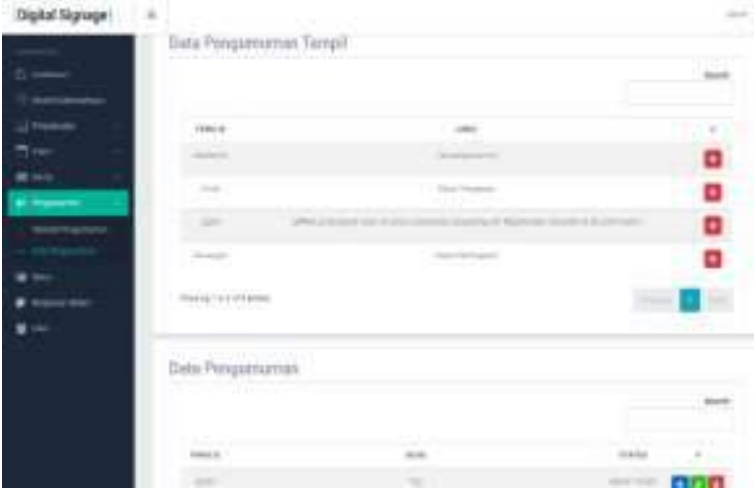

Gambar 14. Tampilan Manajemen Pengumuman

k. Tampilan Manajemen Mata Kuliah

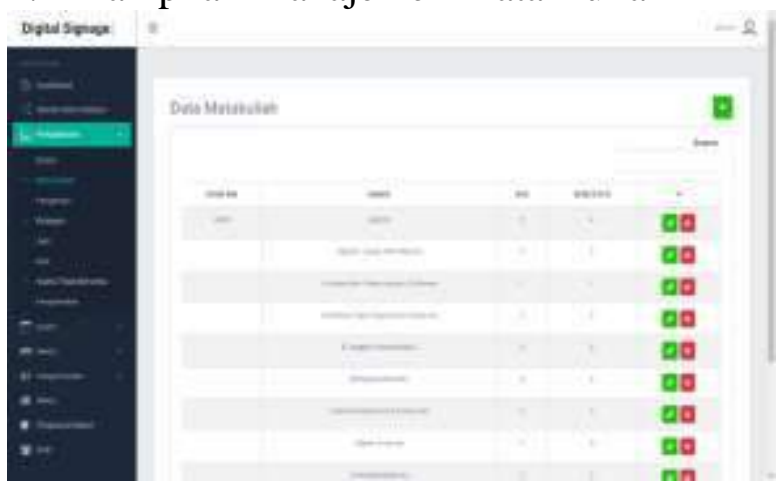

Gambar 15. Tampilan Manajemen Mata Kuliah
1. Tampilan Dashboard

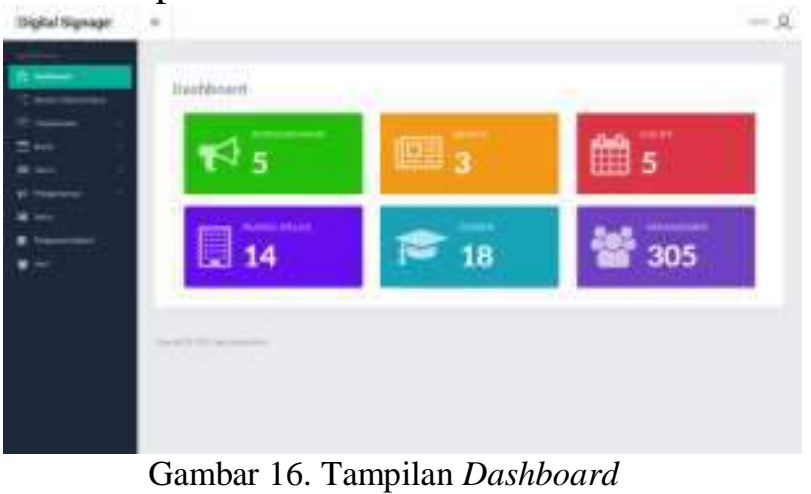

m. Tampilan Form Data Master

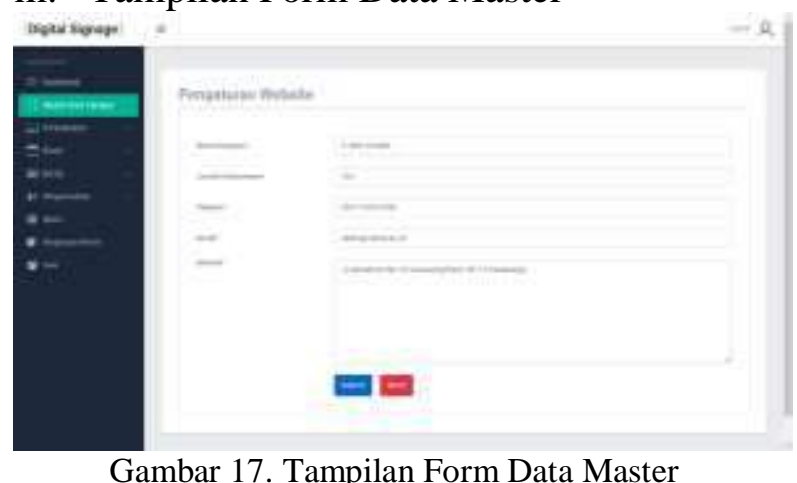

\section{Kesimpulan}

Berdasarkan analisis dan pembahasan yang telah diuraikan sebelumnya, maka dapat diambil beberapa kesimpulan sebagai berikut: (1) Papan Informasi di STMIK Rosma sangatlah penting untuk media komunikasi antara pihak kampus dan mahasiswa, karena tidak selalu mahasiswa bertemu dengan pihak kampus. (2) Papan Informasi yang digunakan di STMIK Rosma masih menggunakan kertas yang ditempel pada mading kampus. (4) Digital Signage menjadikan informasi lebih terpusat dan terkumpul menjadi satu sistem. (4) Menjadikan STMIK ROSMA Kampus IT yang Menerapkan IT dibidang Penyampaian Informasi.

\section{Saran}

Berdasarkan kesimpulan di atas, tentunya masih banyak kekurangan dalam aplikasi yang penulis bangun. terdapat beberapa saran penulis yang dapat dijadikan sebagai masukan diantaranya adalah sebagai berikut: (1) Sistem Digital Signage berbasis web dapat berjalan dengan baik dengan dukungan dari semua pihak. Khususnya dengan adanya administrator yang melakukan control ketika ada pihak kampus yang akan 
memberikan informasi.Aplikasi ini diharapkan bisa melakukan enkripsi banyak symbol khususnya symbol ASCII 256. (2) Digital Signage ini dapat dikembangkan lebih lanjut, sehingga informasi yang disajikan dapat lebih jelas, lebih lengkap serta lebih banyak, agar dapat menjadi suatu sistem yang dapat menyajikan informasi secara lengkap.

\section{Daftar Pustaka}

[1] L. Setiyani, Rekayasa Perangkat Lunak [Software Engneering]. Jatayu Catra Internusa, 2018.

[2] M. M, "SISTEM INFORMASI PENJUALAN BATIK BASUREK BERBASIS WEB PADA BASUREK COLLECTION BENGKULU," J. TAM, no. 09, pp. 52-59, 2013.

[3] F. Muhammad and A. Mulyani, "Pengembangan Sistem Informasi Penggajian di Pesantren Persis 99 Rancabango," J. Algoritm., vol. 13, no. 2, pp. $\quad 348-355, \quad 2017, \quad$ doi: 10.33364/algoritma/v.13-2.348.

[4] A. Solichin, Pemrograman Web dengan $P H P$ dan MySQL. Jakarta: Penerbit Budi Luhur, 2016.

[5] E. Putra and Arifin, "Web Proxy Server Linux Debian 8 Jessie untuk Blokir Situs pada SMK Al-Washliyah Pasar Senen Kota Medan Provinsi Sumatera Utara," J. Ilm. Core IT, pp. 1-12, 2019.

[6] Munawar, Analisis Perancangan Sistem Berorientasi Objek dengan UML. Penerbit Informatika, 2018.

[7] S. R. Serepia, M. R. Julianti, and D. L. Fauzi, "Sistem Informasi Pelatihan Departemen Training PT Gajah Tunggal Tbk Berbasis Web," Sisfotek Glob., vol. 9 , no. 1, 2019.

[8] "What is NGINX?" [Online]. Available: https://www.nginx.com/resources/glossar y/nginx/. [Accessed: 11-Jul-2019].

[9] D. DeJonghe, NGINX Cookbook. O'Reilly Media, Inc., 2019.

[10] A. P. Basuki, "Menguasai Codeigniter: Kasus Membangun Aplikasi Perpustakaan." Loko Media: Yogyakarta, 2016.

[11] A. Subari, "Development of Information System Based on Web Application for Measuring Educational Performance Indicator Using Codeigniter Framework," Adv. Sci. Lett., vol. 24 , no. 12 , pp. 9520 9522, 2018, doi: 10.1166/asl.2018.13064.
[12] Sinopoli, "Video, IPTV, and Digital Signage Systems," J. Smart Build. Syst. Archit. Owners Build., p. 97, 2010. 